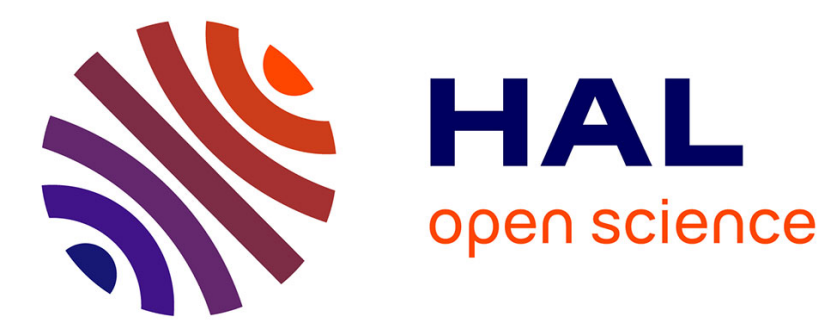

\title{
Validation of automated electronic oestrus detection in sheep as an alternative to visual observation
}

Moutaz Alhamada, Nathalie Debus, Amandine Lurette, Francois Bocquier

\section{To cite this version:}

Moutaz Alhamada, Nathalie Debus, Amandine Lurette, Francois Bocquier. Validation of automated electronic oestrus detection in sheep as an alternative to visual observation. Small Ruminant Research, 2016, Online, pp.97-104. 10.1016/j.smallrumres.2015.12.032 . hal-02636455

\section{HAL Id: hal-02636455 \\ https://hal.inrae.fr/hal-02636455}

Submitted on 27 May 2020

HAL is a multi-disciplinary open access archive for the deposit and dissemination of scientific research documents, whether they are published or not. The documents may come from teaching and research institutions in France or abroad, or from public or private research centers.
L'archive ouverte pluridisciplinaire HAL, est destinée au dépôt et à la diffusion de documents scientifiques de niveau recherche, publiés ou non, émanant des établissements d'enseignement et de recherche français ou étrangers, des laboratoires publics ou privés. 


\section{Accepted Manuscript}

Title: Validation of automated electronic oestrus detection in sheep as an alternative to visual observation

Author: M. Alhamada N. Debus A. Lurette F. Bocquier

PII: S0921-4488(15)30122-X

DOI: http://dx.doi.org/doi:10.1016/j.smallrumres.2015.12.032

Reference: RUMIN 5110

To appear in:

\section{Small Ruminant Research}

Received date:

31-8-2015

Revised date: 4-12-2015

Accepted date: $19-12-2015$

Please cite this article as: Alhamada, M., Debus, N., Lurette, A., Bocquier, F., Validation of automated electronic oestrus detection in sheep as an alternative to visual observation.Small Ruminant Research http://dx.doi.org/10.1016/j.smallrumres.2015.12.032

This is a PDF file of an unedited manuscript that has been accepted for publication. As a service to our customers we are providing this early version of the manuscript. The manuscript will undergo copyediting, typesetting, and review of the resulting proof before it is published in its final form. Please note that during the production process errors may be discovered which could affect the content, and all legal disclaimers that apply to the journal pertain. 


\section{Validation of automated electronic oestrus detection in sheep as an alternative to visual observation}

M. Alhamada ${ }^{a}$, N. Debus ${ }^{a}$, A. Lurette ${ }^{a}$, F. Bocquier ${ }^{a, b^{*}}$.

a INRA, UMR868 Systèmes d'élevage méditerranéens et tropicaux, F-34000 Montpellier, France

${ }^{\mathrm{b}}$ Montpellier SupAgro, Dept. MPRS, F-34000 Montpellier, France

*corresponding author at: Montpellier SupAgro, UMR SELMET, 2 place P. Viala, Bât 22, F34060 Montpellier Cedex 1, France. Tel.: +33(0) 4996121 12; fax: +33 (0) 4675456 94;

E-mail address: bocquier@supagro.fr 


\section{Highlights}

- This new oestrus detector is bases on RFID reading of ewes by an equipped ram.

- Remote data transfer does not necessitate animal handling.

- Efficiency of standing oestrus detection is similar to video observations.

- This detector fits to natural or hormonally induced estrus in the ewe.

- This is a promising tool for behavioral researches in both males and females.

\section{ABSTRACT}

The objective of this work is to determine the efficiency of the electronic oestrus detection system Alpha-Detector (AD) in sheep. Males are equipped with a harness carrying the electronic device. This original system consists of a custom RFID reader which is triggered at the time of mounting to read the transponder that is placed on the females' rump. This detector stores the ID number of ewe together with date and time of each mount. Two trials were developed with Merinos d'Arles sheep. In Trial 1, visual observations (VO, i.e. continuous video records) were compared to readings made by 2 rams on 12 ewes. Ewes were allocated into two groups and were followed up for a period of two oestrous cycles i.e. hormonally induced oestrus (C1) and natural oestrus (C2). In Trial 2, 30 ewes tagged with a caudal transponder were naturally sired by a ram equipped with AD. In Trial 1 , despite a widespread of the number of mounts per ewe (i.e. from 2 to 83), the $\mathrm{AD}$ allowed detection of $100 \%$ of the females that came in oestrus (11/12 in C1 and 8/12 in C2). Hence, when considering only standing oestrus, the coincidence of true mounts reaches $94 \%$ (342 readings /364 observed mounts). With regard to males' sexual activity, the first ram M1 did 242 mounts, while only 110 mounts were recorded for the second male M2. Overall Khi-2 analysis confirmed highly significant $(\mathrm{p}<0.0001)$ difference in male activity both due to a male difference (M1 > M2) and to a cycle effect $(\mathrm{C} 1>\mathrm{C} 2)$. This decline of sexual activity is assumed to be due to the onset of seasonal anoestrous.

In Trial 2, oestrus occurrences, signaled by frequent mountings of the ram, were constantly distributed along time. All ewes displayed an oestrus during the first cycle (C1 i.e. 17 days with the first ram). There is also a wide range in the number of mounts per ewes (from 3 to 205). Remarkably, 2 ewes that were mounted during first cycle came back in oestrus 17 days later as revealed by frequent mountings of the second ram in C2. Lambing dates confirmed the time of conception observed with the AD. As observed in Trial 1, it is however necessary to discard isolated mounts that occurred just after male introduction and did not correspond to standing oestrus (no further readings within 6 hours).

With the AD device $100 \%$ of oestrus ewes were detected. Many researches on reproductive physiology and behavior that can be developed with this device are presented for small-ruminants at large.

Keywords: Ewe; Ram; Oestrus; Electronic oestrus detection; Visual observations, Sexual behavior. 


\section{Introduction}

Efficiency of reproduction in a sheep flock depends on both male and female factors. On the male side it is well known that ram sexual behavior is rather different amongst individuals although the general behavioral pattern is conserved (Price et al., 2000; Bench et al., 2001). This has been confirmed by the beneficial effect on the overall fertility of controlling ram libido before servicing in the flock (Alexander et al., 2012). On the female side, it is of major concern to reliably detect females in estrus especially when Artificial Inseminations (AI) are to be performed. The only field indicator that a female is in oestrus is her acceptance of the male in mounting. Using this indicator, the most widely used technique for recording the occurrence of oestrus employs a marker crayon on the male (Radford et al., 1960), along with periodic visual observations of the females. At best it is inconvenient to observe mating directly and under field conditions it is usually impossible to do so, not to mention of the time this required to make repeated observations, errors due to poor or improper marking, and the inability to determine the number of mountings per oestrus period. Other techniques include video recording for continuous monitoring, these technics also have obvious disadvantages. Furthermore, for males and females of small-ruminants an important peculiarity is that sheep and goats are seasonal breeders (Ortavant et al., 1988). This further re-inforces the interest of estimating females' sexual activities (ovarian cyclicity and estrous behavior) along the year.

In ruminants, most of progresses in monitoring oestrus occurrence have been made in dairy cows probably because the costs of subfertility (Boichard, 1990) are far higher than in small ruminants. The second cause may be the extensive use of hormonal treatments in sheep and goats in developed countries that allows mating or insemination at fixed time, i.e. without checking occurrence of oestrus in the females (Colas, 1979 in the ewe; Corteel et al., 1988 in the goat) whatever the season. In cattle, available oestrus detection devices are based on measurements of changes in sexual behavior through individual mountings among cows (HeatWatch ${ }^{\circledR}$; Peralta et al., 2005; DEC ${ }^{\circ}$; Saumande, 2002) or through activity-meters (HeatTime: At-Taras and Spahr, 2001; Valenza et al., 2012). Camera-software systems sometimes replaced direct visual observations of female behavior (Bruyère et al., 2012; Peralta et al., 2005). For this purpose, direct endocrine parameters of the oestrous cycle have also been used including milk progesterone (Firk et al., 2002) or indirect ones like changes in body temperature (Geers et al., 1997). The heat detection rate of most of these devices is above $70 \%$ with a specificity of detection generally above $90 \%$ (Saint-Dizier and ChastantMaillard, 2012; Firk et al., 2002).

Based on automated measurements of males and females sexual behaviors, an original device has been developed for heat detection in sheep (Bocquier, 2005). Due to the flock size in small ruminant equipping each female, like in cattle, would be prohibitive. This is probably the reason why no device has been yet proposed. In addition, up to now, AI are mostly performed on females that have been previously synchronized. This however is not allowed in organic farming system, preventing breeder from performing AI. The only possibility would be to carry out insemination of females possibly synchronized by a male effect (Bocquier et al., 2009) if oestrus detection could be done easily.

The objective of the present work is to evaluate the efficiency and specificity of this original electronic device that records males’ mountings of females in estrous. For this aim, rams, that were equipped with the electronic device, were put with ewes that were either hormonally synchronized (Trial 1) or naturally mated (Trial 2). 


\section{Materials and methods}

All experiments were approved by INRA and Regional Ethic Group Montpellier and were compliant with the Animal Research Act 1985 in accordance with ethical principles that have their origins in the European Union directive 2010/63/EU.

\subsection{First trial (T1)}

\subsubsection{Animals and treatment groups}

This experiment was conducted in SupAgro domain du Merle (Lat. $43.64^{\circ} \mathrm{N}$, Long. 5.02 ${ }^{\circ} \mathrm{E}$ ) in southeastern France. Twelve multiparous Merinos d'Arles ewes $(45.2 \pm 6.2 \mathrm{~kg}$, mean $\pm \mathrm{SD}$ ) were allocated in two groups and their cycles were blocked with progestagen $(20 \mathrm{mg}$ fluorogestone acetate (FGA) impregnated vaginal sponge for 14 days, (Chronogest CR, Intervet) and synchronized with an injection of gonadotropin (400 IU equine chorionic gonadotropin (eCG), Intervet) at time of sponge removal. Ewes were followed up during their two cycles (C1 induced and C2 natural) in spring (starting on the $5^{\text {th }}$ of April). Two vasectomized rams (one male per group: i.e. M1 and M2) equipped with Alpha Detectors (AD) were introduced at the time of sponge removal. They were kept 4 days (C1), then removed for 12 days and then re-introduced in the opposite group of females for a 5-days period (C2) (Fig. 1). The experimental barn was equipped with two video cameras. These cameras were connected to a computer that continuously recorded video files in order to follow the behavior of animals thanks to painted identification on the back of ewes. Noted behaviors were mount attempts (the ram raises his front feet but it does not settle firmly over the female) and standing mounts (the ram settle soundly on the ewe). Artificial lighting allowed night recordings. These ewes were normally fed with hay and straw. They had free access to water.

\subsection{Second Trial (T2)}

\subsubsection{Animals and treatment groups}

This trial was conducted in INRA experimental station of Fréjorgues near Montpellier (Lat. $43.59^{\circ} \mathrm{N}$, Long. $3.96^{\circ} \mathrm{E}$ ). Thirty adult Merinos d'Arles ewes were randomly chosen in the flock for having previously lambed (bodyweight $53.9 \pm 4.2 \mathrm{~kg}$ ). These ewes were normally fed twice daily and had free access to water. A fertile ram ( $\left.{ }^{\circ} 6061\right)$, equipped with the electronic device (AD), was introduced at the beginning of the trial (October $21^{\text {th }}$ ) and was further removed after 17 days and being immediately replaced by another equipped fertile ram $\left(n^{\circ} 1429\right)$ until the end of observations (November $14^{\text {th }}$ ). Animals were considered to be in their sexual season (i.e. Fall). Blood samples were taken on day 30 and 62 after the end of trial to obtain an early pregnancy diagnosis by mean of dosing plasma PSPB (El Amiri et al., 2003). In addition lambing dates allowed determining if ewes were fertilized during their first or their second oestrus.

\subsection{Electronic oestrus detection system application (for T1 and T2)}

Automated heat detection is based on a standalone special reader (Alpha-Detector ${ }^{\circledR}$, Wallace, Cardet-France) worn by the male, which records the electronic identifier of a female accepting mountings. This detector, located in a leather pouch, is positioned between the front legs of the male by a harness (Fig. 2). When mounting, a sensor triggers the reading process of all nearby transponder. The closest transponder being the one bonded to the tail of the mounted female. This transponder is installed by adhesive tape at the top of the female's tail, 
and it does not lead to a change in the behavior of male (Bocquier et al., 2009). At each reading, the identifier of the female, the exact date and time are recorded in a file. On request, the stored data are transferred from the $\mathrm{AD}$ to a handheld device (Alpha-Receptor ${ }^{\circledR}$, Wallace, Cardet France) or to a notebook connected to a specific radio antenna. The remote transfer of data $(>100 \mathrm{~m})$ is done by a radio frequency signal. The female transponders were Half Duplex (HDX) Tiris ${ }^{\circledR}$ Glass Transponders (32×3.8 mm; model RI-TRP-WR2B; GIOTEX, Barcelona, Spain) which complies with 11784/11785 ISO standard for animal identification.

\subsection{Data manipulation and statistical analysis}

For both trials, results expressed as individuals mountings (or readings) were computed against time and further analyzed with classical statistics performed with Microsoft 10.0 Excel Spreadsheet. Data are expressed as time elapsed since sponge removal (T1) or ram introduction (T2) and shown as cumulative number of readings per ewe. The factorial design of Trial 1 allowed comparisons of factors such as C1 vs. C2, and rams effect M1 vs. M2. As most of the data consisted of number of readings or mountings, they have been analyzed by Khi-2 test. Results are presented as means $\pm \mathrm{SD}$, with a $P$ value $<0.05$ indicating statistically significant differences between groups.

\section{Results}

Rams that were equipped with Alpha Detector (AD), as ewes with a glued transponder on the tail, did not show any peculiar behavior related to these equipment. It is worth noticing that in Trial 1, rams were prevented from siring while in Trial 2 they could sire and thus may have exhibited refractory periods without any mounting.

\subsection{Trial 1, validation of the electronic device carried by rams on hormonally synchronised ewes}

Eleven out of twelve ewes displayed oestrus behavior after hormonal treatment in C1, but on the following cycle C2 only eight out of twelve ewes exhibited oestrous behavior. Video observations (VO) were all analyzed visually and times of occurrence of mountings were noted. Ewe acceptances of male mountings were qualified as either standing or escaping male attempts. Video observations were considered as the reference method (Fig. 3). Data obtained by $\mathrm{AD}$ was compared to timing of mountings seen on video records. Because of an $\mathrm{AD}$ malfunctioning at the beginning of the trial, the first 12 mounts among the 30 for the Ewe_E that were noted by video but not recorded by AD were not taken into account (see Fig. 3: the Ewe_E at 17:00 on the first day). For the rest of the trial we did not observe any other malfunction of the AD. All females that were detected to be in oestrus by the VO method were also detected by $\mathrm{AD}$, although there was a wide difference among ewes in the total number of mounts. This was particularly the case (Fig. 3) for one female (at least) in each group that accepted numerous mounts i.e. 41 and 83 respectively for Ewe_3 (C2) and Ewe_B (C1). On the other hand, some ewes accepted very few mounts i.e. 11 and 2 for Ewe_4 (C1) and Ewe_A (C1) respectively (Fig. 3).

With VO data, the mean time elapsed since the withdrawal of sponges and the appearance of oestrus was of $29 \pm 8 \mathrm{~h}$, with the first ewe being mounted occurring 18 hours after the sponge withdrawal. It was found that the average duration of oestrus was of 15 hours 
( $15 \pm 8 \mathrm{~h}$ in $\mathrm{C} 1 \mathrm{vs} .15 \pm 7 \mathrm{~h}$ in C2) the overall value being of $15 \pm 7 \mathrm{~h}$. The period between the two successive cycles was on average of $16 \pm 0.8 \mathrm{~d}$.

Video observation analysis revealed a total of 414 mounts for the two cycles i.e. 270 in C1 and 144 in C2, while AD recorded a total of 352 mounts i.e. 240 in C1 and 112 in C2. Hence, $85 \%$ of VO records (352/414) were in agreement with AD (resp. 89 \% in C1: 240/270 and $78 \%$ in C2: 112/144). As can be seen in Figure 3 (smaller symbols), the disagreement between VO and AD records only occurred at the beginning or at the end of each estrus sequence. During these periods, ewes exhibit an escaping behavior when a ram attempted to mount. We therefore decided to suppress these observations and/or the AD records when ewes did not exhibit a clear standing behavior. This suppression leads to a significant improvement of the results. Hence, when considering only standing oestrus ewes, the coincidence of true mounts reaches 94\% (342/364) and slightly differed between C1 (97\%, 236/244) and C2 (88\%, 106/120).

With regard to male sexual activity, without taking into account potential ewes' escaping behavior, 242 AD mounts were recorded for the first ram M1 (145 in C1 and 97 in C2), while 110 mounts were recorded for the second ram M2 ( 95 in C1 and 15 in C2) (Fig. 4). Overall Khi-2 analysis confirmed highly significant $(P<0.001)$ difference in male activity both due to a male difference (M1 vs. M2) and to a cycle effect (C1 vs. C2), the ranking of both factor being maintained. Estimated male difference was of 132 mounts (M1-M2) and cycle difference (C1-C2) of 128 mounts. With this model, the theoretical distribution of mountings follows the subsequent rules: the mean mounts of cycle C1 is twice (2.14) higher than cycle C2 and the mean mounts by M1 ram is twice (2.2) higher than for the M2 ram. Due to the limited difference between $\mathrm{AD}$ and $\mathrm{VO}$ the same tendency were observed when using only VO method i.e. ram effect (M1-M2 = 54 in C1 and 96 in C2) and cycle effect (C1$\mathrm{C} 2=42$ for M1 and 84 in M2).

\subsection{Trial 2, validation of the electronic device as oestrus detection system in a flock of ewes naturally mated}

As one could expect (Fig. 5), oestrus occurrence in natural conditions have a steady distribution along time after the first ram $\left(n^{\circ}\right.$ 6061) was introduced and remained with the ewes for the 17 days of observation (i.e. first cycle). While for the second oestrous cycle, only unfertilized ewes expressed oestrus behavior (2 ewes with ram $n^{\circ} 1429$ ). Just after introduction of each ram a number of isolated readings were observed (not shown). As observed in Trial 1, we confirmed that theses ewes were then not in oestrus because a high frequency of successive readings was observed later on and within 17 days: i.e. exhibition of a classical oestrus behavior. Eliminating the readings that were not followed by other readings within a 6 hours period allowed a useful filtering of the data. We observed 51 of such readings amongst a total of 1789 readings that were collected i.e. less than $3 \%$. It was chosen to automatically discard these $3 \%$ elementary mountings with a simple algorithm that eliminates the readings which are not repeated within $6 \mathrm{~h}$. The remaining points were therefore considered as oestrus behavior of the ewe i.e. repeated acceptance of mounts by the ram. Hence, the mean number of collected readings per ewe was of 59 but these were highly variable $( \pm 48)$. In fact it ranged from 3 to 205 per ewe per cycle, but all the 30 ewes showed estrus. One can see on Figure 5 that two ewes that were respectively detected with 22 and 23 readings during their first cycle came back in oestrus exactly 17 days later (i.e. the theoretical duration of an oestrous cycle in the ewe). During their second cycle they were then respectively read 26 and 51 times by the other ram ( $\left.{ }^{\circ} 1429\right)$. The pregnancy diagnostic tests, together with lambing dates, showed that whatever the number of readings ewes were 
fertilized. Hence the fertilization does not depend on number of readings since for 4 ewes, it occurred with less than 15 readings. In addition, the mean duration of ewes in natural oestrus, computed on filtered data, was of $24.4 \pm 13.0$ hour.

\section{Discussion}

This original electronic device (Alpha-Detector), that automatically records timings of standing mounts by a ram equipped with a special reader, is evaluated here for the first time in Trial 1. The cause of initial malfunctioning of AD was clearly identified since no manual reading of any transponders was possible with this $\mathrm{AD}$. With regard to the malfunctioning of one of the detectors at the beginning of the experiment (12 mounts in Ewe_E) this led to a low rate of overall specificity that dropped to $88 \%$ for this ewe. This problem was rapidly solved by replacing the detector. Following version of $\mathrm{AD}$ has been improved in this way. Anyway, such risks exist if there are defaults in the card detector or corruption in the transmission of the wireless signal or absence of functioning transponder and of course if the battery is drained. We therefore recommend checking all these points before measurements.

The implemented continuous video recording (equivalent to visual observation: VO) of animal behavior offered the possibility to observe them without risk of missing sudden animal reactions. It also allowed following carefully the identity of each female, preventing from any false identification. As expected there was no false positive detection due to the reading of a transponder of an un-mounted ewe. This was due to the technical choice of triggering the transponder reading only when mounting a ewe. Furthermore, as far as reading are only possible within a short distance (i.e. 10 to $15 \mathrm{~cm}$ ) of the antenna located between the front legs of the ram no other ewe's identifier can be catch.

Considering that all observed (VO) mountings should have been detected by AD gave a modest overall efficiency of $85 \%$. As observed on video records all of the points that were not accompanied by $\mathrm{AD}$ readings corresponded to ewes that were not in standing oestrus and thus should not be considered in the process of oestrus detection. This is also the case in classical method of oestrus detection (Stellflug et al., 2008) by following a ram in contact with ewes: not all the mounting attempts are counted. According to Banks (1964), ewe is in oestrus if it "stands still when approached by the male and remains standing while the ram nudges or may walk off a few steps and stand again”, but Edey et al., (1978) and Fabre-Nys and Venier., (1987) showed that some ewes although mounted, did not stand when the male approached. These females often show an ambiguous response to male mounting as well as to male courtship. They accepted and refused mounting alternately and so could be either classified as in oestrus or not in oestrus. However, ewes showing a full oestrus response always accepted mounting and stood firmly when courted. When ignoring these isolated readings, the resulting efficiency of reading with ewes accepting ram's mounts reached $94 \%$. In all cases, either with 85 or $94 \%$, this efficiency is sufficient to detect $100 \%$ of ewes in oestrus as far as several mounts are frequently recorded. In the present situation, the minimum number of mounts observed was then of 2 (Trial 1; Ewe_A, C1). In Trial 2 we observed that each ram attempted to mount ewes just after its introduction in the group of females $\left(\mathrm{N}^{\circ} 6061\right.$ in $\mathrm{C} 1$ and $\mathrm{N}^{\circ} 1429$ in C2). Finally this problem was solved by filtering data from isolated readings. 
In the published papers on cattle, only global results (in oestrus or not in oestrus) are reported, but elementary results as presented in our work are not available. Hence, any direct comparison can be done with the efficiency of the present device except when analyzing the ewes that were ratified to be in oestrus after several reading being counted. In the present trials $100 \%$ of the ewes in oestrus were detected. When comparing our results with previous data obtained in dairy cattle by different methods, AD efficiency is clearly above the published values. First, one should remember that even the direct continuous visual method gave contrasting detection rates i.e. from 69\% (Valenza et al., 2012) to 93\% (Saumande, 2002) depending on many factors including nonspecific behaviors of other cows in the herd. The best results of detection were found using pedometers 90-98\% (Firk et al., 2002) which do not depend on counterpart behavior. With the HeatTime ${ }^{\circledR}$ device, an individual accelerometer, the accuracy was comprised between 71\% (Valenza et al., 2012) and 79\% (AtTaras and Spahr, 2001). With devices detecting pressure during mounts, like HeatWatch ${ }^{\circledR}$ device glued on the back of the cow the detection rate was of $69 \%$ in Holstein-Friesians cows (Palmer et al., 2010), while the detection rate was of 87\% with the DEC $®$ device (Saumande, 2002). Comparisons of these devices are however difficult since the efficiency of oestrus detection varies depending on the threshold values (i.e. the number of elementary events) used in the apparatus and methods for time series analysis (frequency of elementary events) which are not given. Fundamentally these thresholds depend on cow's ability to exhibit oestrus behavior: namely cows' density, slippery floor and lameness that may restrict mounting activities. Although the pedometer technology is the best to detect oestrus in cow (Firk et al., 2002) it is also affected by lameness, transition buildings/grazing (Holman et al., 2011) or any changes in the animal routine. In cattle, the heat mounts detector is a method widely used that gives acceptable results, but the dislodging of the detector leads to loss of information and thus loss of money, effort and time for breeders (Holman et al., 2011). Altogether these methods are still imprecise in giving the optimal time of insemination.

In small ruminants, the detection of oestrus by using marker rams (coloring the animal back and rump; Radford et al., 1960) is the most common way of detecting ewes in oestrus, but it is a quite imprecise method largely subjected to breeder's attention. It needs observations of the marks on the females' back once or twice a day. Furthermore this cannot give with certainty the onset of oestrus; therefore the optimal time of insemination is unknown. In addition it needs a lot of time and effort of breeder who needs to catch the rams and change the crayons to keep the marker working. This might not be the case with AD since batteries can last more than a week, and accumulated data can be remotely downloaded within approximately $100 \mathrm{~m}$ range without any handling of the males.

In all studies published on oestrus detector, the specificity rate (SR), which is the proportion of mounts out of false-positive number, is given. This SR criterion is necessary for devices that rely on nonspecific behavioral components i.e. nonspecific mountings, nonsexual intense activities, inadequate markings, changes in body temperature etc. Thus SR must be considered with devices that rely on mountings among counterparts cows (HeatWatch ${ }^{\circledR}$, DEC ${ }^{\circledR}$,) or physical activities (Heatime ${ }^{\circledR}$ ) with or without oestrus. According to peculiar algorithm used to detect specific sexual activity signals, the SR is generally comprised between $90 \%$ and $98 \%$ in the cows equipped with HeatTime ${ }^{\circledR}$ (Saint-Dizier and Chastant-Maillard, 2012) and between 96\% and 98\% for pedometers according to Firk et al. (2002). In the present study, we argued that the SR is high because AD is equipping males (even if vasectomized or prevented from siring) with a reader located between the ram's front legs making readings specific of sexual activities. The male makes the difference between a 
receptive and unresponsive female by smelling urine, sniffing, flehmen, kick legs up which are part of the normal behavior of the male against ewe (Parson and Hunter, 1967; Fabre-Nys and Venier., 1987). But this high specificity of AD is also mostly explained by the ewes' oestrus behavior; the ewe researches and remains in contact with the male. Lastly this specificity is reinforced by the position of the transponder which is located on female rumps and that can only be read during mounting. A lack of specificity however exists with $A D$ as discussed before. False positive readings may be encountered with isolated mountings of ewes that are not in oestrus. This later problem is solved by filtering of data without any visual proof. In the situation were several males are in use, if such isolated readings are not confirmed by other rams' mounts, they should be ignored. In Trial 2, the proposed window filter was of 6 hours with a single ram for 30 ewes. This rule can be improved by adjusting this threshold to local conditions. On the other hand the high SR of AD device relies on the behavior of the ewe that does not accept mountings when not in oestrus (Bank., 1964; Edey et al., 1978; Fabre-Nys and Venier., 1987). To conclude on this point, SR value of AlphaDetector might be close to $100 \%$ if decision is made to ratify ewes in oestrus only when they are frequently mounted by several rams within a short period.

Furthermore, the $\mathrm{AD}$ device is characterized by accurate recording of each time mounts (hour, minute, second) and stores the unique identification of each of the females successfully mounted. In addition, ease of data analyses which are transmitted to the Alpha-R terminal via a wireless signal allows a frequent control of ewes' sexual status allowing a nearreal time determination of the onset of oestrus. This might help to develop a precise agenda to ensure success of IA by virtue of real pattern of oestrus behavior. For the majority of sheep concerned by artificial insemination (AI) absence of oestrus detection in a timely and accurate manner is the main limiting factor toward obtaining efficient reproductive performance. Many factors lead to different proportion of ewes in response to hormonal treatment, Umberger et al., (1994) found 79\% of ewe responded to treatment with FGA while Makawi et al., (2007) showed $80 \%$ of ewe responded. In the present experiment (Trial 1) we observed that at least one ewe over 12 did not responded to hormonal treatments. In practical conditions the proportion of ewe responding to hormonal treatment is largely different and in on farm situations reduced fertility rates the absence of response in ewes cannot be rule out. Meanwhile in goats this problem of inefficiency of hormonal treatment has been clearly related to immunization against eCG after several applications of this treatment (Brown et al., 1995).

Hormonal treatments based on impregnated FGA sponges in association with an eCG injection was proved to induce oestrus even in noncyclic ewes (Umberger et al., 1994; Contreras-Solis et al., 2009). In Trial 1 this was confirmed although one ewe in twelve did not express any behavior that could be detected by rams. On the following cycle (i.e. $+17 \mathrm{~d}$ later) the proportion of non-cycled ewes increased (4/12). One can hypothesize that seasonal anoestrus fades the inductive process of hormonal treatments lowering the number of ewes that exhibit oestrus (8/12). In fact at this period (i.e. April $\left.5^{\text {th }}\right)$, Merinos d'Arles ewes are mostly in anoestrus (10/12; Teyssier et al., 2011), even if this proportion varies across years. This was also the case with other Merino ewes that were partially non-cycling at this period (22\%, 11/50; Lamond, 1964).

The classical method to determine estrus duration is to observe a ram every 4 hours when put in contact with ewes. This is a strong constraint for the animals and the breeder (Stellflug et al., 2008). With AD, that continuously monitor the ram behavior (even during the night), we found that the mean duration of oestrus in Trial 1 was of 15 hours. This is 
consistent with the previous findings (Parson and Hunter, 1967) who reported that, in Merino sheep, the period during which teaser rams would mate with the test ewes was significantly reduced from a mean of about 22 hours in groups entirely separated from rams between teasing, to 11 and 16 hours when sexually active rams were remained with the ewes throughout oestrus (8-16 h, Lindsay et al., 1975). Trial 2 gave even more reliable results due the greater number of ewe per ram (i.e. 30). As ram had choice of mounting any ewe that was in oestrus and accepted mountings, it is not surprising to observe a large variability in the number of mounts per ewe due to the number of ewes that were simultaneously in oestrus (see Fig. 5). As the libido of the ram or it serving capacity might be limiting (Price et al., 1992), the number of mounts logically diminishes with the increasing number of ewes that are simultaneously in oestrus. This may explain the observed low number of mounts on some of the ewes. Inversely, the high number of mounts (i.e. 205 and 157; see Fig. 5), may be explained by ram preferences for some of the ewes. However, only an appropriate design with ewes taken off could evaluate this ram preference (Tilbrook et al., 1987). As a consequence, the fertilization of ewes could not be related to the number of mountings. This was not surprising since firstly the AD cannot prove that ejaculations occurred and secondly a ram cannot mount all the ewes within the same period thus limiting the number of mounts per ewes.

In Trial 2, estimated oestrus duration of these Merinos d'Arles ewes, which was shorter than a day (i.e. 20.4 \pm 13.0 h), is longer than the value established in Trial 1 (i.e. $15.0 \pm 7$ h). Cognié et al., (1970), showed that there is an effect of season between April and September on the duration of oestrus in ewe, the longer values being observed during the breeding season (Autumn, Trial 2) while a shorter duration is observed in late winter (Trial 1). Altogether, values found here are in general agreements with previously published values. In the Greek Merinos ewes (Moise et al., 2012), the range of oestrus duration is in between 2-92 hours, with an average value of $24-36 \mathrm{~h}(86.1 \%$ of ewes). The very short $(<12 \mathrm{~h}, 3.4 \%)$ and very long (>60h, 0.6\%) oestrus durations being exceptions (4\%). New Zealand Merino ewes were reported to have rather short oestrus durations i.e. 12.8 $\pm 0.9 \mathrm{~h}$ in May (Allison and Davis 1976). These differences may be due to age and geographical location. Hence, the origin of the variability of the oestrus duration seen in Trial $2( \pm 13.0 \mathrm{~h})$ remained mostly unknown. This variability may be confounded with the method of oestrus detection (visual detections are done every 4 or 6 hours) and the sheep breed $x$ location interaction. On a practical point of view, the present electronic device that can be downloaded remotely may directly alert the farmer on the occurrence of oestrus in the flock whatever the dispersion of oestrus, thus allowing adaptations of strategy of reproduction (i.e. AI or natural mating), without any perturbation due to animals handling.

\section{Conclusion}

This electronic device, that gives a reliable detection of mounted ewes, can be used to detect oestrus provided that isolated points, especially just after male introduction, are ignored. This can be easily achieved by filtering readings through algorithms including mounts frequency and number of different rams mounting the ewe. Alpha-Detector is validated for precise determination of oestrus behavior in all ewes synchronized (Trial 1) or in spontaneous (Trial 2) estrous cycle. One important feature is that all the females are susceptible to be detected provided that a passive transponder was permanently placed on their rump. While with the available cow's oestrus detection systems all cows must be transiently equipped with a pedometer or with a harness unless they cannot be detected. This means that once a 
transponder has been fixed to the female's rump no extra handling is necessary. Furthermore, $\mathrm{AD}$ allows detecting females that are not fertilized and returned to oestrus which is not possible with cow devices without re-installing it.

This Alpha-Detector, which was used on the Mérinos d'Arles breed, can serve to better understand reproductive physiology of any small ruminant female including goats. AD allows automated measurements of the onset of oestrus, its duration, its intensity according to different experimental conditions (breed, age, parity, including response to male effect according to nutritional status and other factors). Male's libido can also be quantified with this device by ranking males tested on a common batch of ewes in oestrus (see Price et al., 1992). This device may also greatly help improving reproductive technologies at the farm level (AI, embryo transfer) by giving precise timing of oestrus. Lastly, such a detector may become a new tool available for breeders and technicians that could become a part of livestock precision farming system for small ruminants. It is expected that such a device leads towards environmentally friendly, precise, profitable agriculture and shorten the time and effort's breeder.

\section{Acknowledgements}

This work was part of BERCAIL project funded by FEDER and OSEO and Transfert-LR. Moutaz Alhamada is supported by a scholarship from the University Al-Furat, Syria. We thank the technical staff of Le Merle experimental station (Montpellier SupAgro); P.-M. Bouquet, C. Maton, and J.-D. Guyonneau, and Montpellier technical staff; G. Viudes and J.M. Capron. 


\section{References}

Alexander, B.M., Cockett, N.E., Burton, D.J., Hadfield, T.L., Moss, G.E., 2012. Reproductive performance of rams in three producer range flocks: Evidence of poor sexual behavior in the field. Small Rumin. Res. 107, 117-120.

Allison, A.J., Davis, G.H., 1976. II. Effects of age of ewe, live weight, and paddock size on duration of oestrus and ram-seeking activity. New Zealand Journal of Experimental Agriculture. 4, 269-274.

At-Taras, E.E., Spahr, S.L., 2001. Detection and Characterization of Oestrus in Dairy Cattle with an Electronic Heatmount Detector and an Electronic Activity Tag. J. Dairy Sci. 84, 792-798.

Banks, E.M., 1964. Some aspects of sexual behavior in domestic sheep, Ovis aries. Behavior, 23, 249-279.

Bench, C.J., Price, E.O., Dally, M.R., Borgwardt, R.E., 2001. Artificial selection of rams for sexual performance and its effect on the sexual behavior and fecundity of male and female progeny. Appl. Anim. Behav. Sci. 72, 41-50.

Bocquier, F., 2005. Patent, Agro.M, INRA-PHASE, Method and device for automatically detecting mating of animals. WO 2005065574 A1

Bocquier, F., Viudes, G., Maton, C., Debus, N., Gibault, L., Teyssier, J. 2009. Use of electronic identification for automated oestrus detection in livestock. 60th Annual Meeting of the European Association for Animal Production, Barcelone, Spain, pp. 485.

Boichard, D., 1990. Estimation of the economic value of conception rate in dairy cattle. Livest. Prod. Sci. 24: 187-204.

Brown, B.W., Mattner, P.E., Carroll, P.A., Hoskinson, R.M., Rigby, R.D.G., 1995. Immunization of sheep against GnRH early in life: effects on reproductive function and hormones in ewes. J. Reprod. Fertil. 103, 131-135.

Bruyère, P., Hétreau, T., Ponsart, C., Gatien, J., Buff, S., Disenhaus, C., Giroude, O., Guérin, P., 2012. Can video cameras replace visual oestrus detection in dairy cows?

Theriogenology. 77, 525-530.

Cognie, Y., Mariana, J.C., Thimonier, J., 1970. Etude du moment d'ovulation chez la Brebis normale ou traitée par un progestagéne associé ou non à une injection de PMSG [Time of ovulation in the ewe following progestagen and PMSG treatment]. Ann. Biol. Anim. Biochim. Biophys. 10, 15-24.

Colas, G., 1979. Fertility in the ewe after artificial insemination with fresh and frozen semen at the induced oestrus, and influence of the photoperiod on the semen quality of the ram. Livest. Prod. Sci. 6, 153-66.

Contreras-Solis, I., Vasquez, B., Diaz, T., Letelier, C., Lopez-Sebastian, A., Gonzalez-Bulnes, A., 2009. Efficiency of estrous synchronization in tropical sheep by combining shortinterval cloprostenol-based protocols and 'male effect". Theriogenology. 71, 10181025.

Corteel, J.M., Leboeuf, B., Baril, G., 1988. Artificial breeding of adult goats and kids induced with hormones to ovulate outside the breeding season. Small Ruminant Research. 1: 19-35.

Edey, T.N., Kilgour, R., Bremner, K., 1978. Sexual behaviour and reproductive performance of ewe lambs at and after puberty. The Journal of Agricultural Science 90, 83-91.

El Amiri, B., Karen, A., Cognie, Y., Sousa, N.M., Hornick, J.L., Szenci, O., Beckers, J.F., 2003. Diagnosis and monitoring of pregnancy in sheep: reality and perspectives (French). INRA Prod. Anim. 16, 79-90. 
Fabre-Nys, C., Venier, G., 1987. Development and use of a method for quantifying female sexual behaviour in ewes. Applied Animal Behaviour Science. 17, 289-304.

Firk, R., Stamer, E., Junge, W., Krieter, J., 2002. Automation of oestrus detection in dairy cows: a review. Livest. Prod. Sci. 75, 219-232.

Geers, R., Puers, B., Goedseels, V., Wouters, P., 1997. Electronic identification, monitoring and tracking of animals. CAB International, Wallingford, New York, pp. 45-46.

Holman, A., Thompson, J., Routly, J.E., Cameron, J., Jones, D.N., Grove-White, D., Smith, R.F., Dobson, H., 2011. Comparison of oestrus detection methods in dairy cattle. Vet. Rec. 169, 47-52

Lamond, D.R., 1964. Seasonal changes in the occurrence of oestrus following progesterone suppression of ovarian function in the Merino ewe. J. Reprod. Fertil. 8, 101-114.

Lindsay, D.R., Cognié, Y., Pelletier, J., Signoret, J.P., 1975. Influence of the presence of rams on the timing of ovulation and discharge of LH in ewes. Physiol. Behav. 4, 423-426.

Makawi, S.A., Manahil, Z.A., 2007. Fertility response of desert ewes to hormonal oestrous synchronization and artificial insemination using fresh diluted semen. Journal of Animal and Veterinary Advances. 6, 385-391.

Moise, L., Sonea, A., Moise, V., 2012. Analyze of average duration of pregnancy and oestrus in sheep breed Merino Palas and Tigaie. Conference: International Symposium "Modern zootechnics, factor of sustainable development", USAMV Iasi, Romania, 26-27 April 2012.

Ortavant, R., Bocquier, F., Pelletier, J., Thimonier, J., Volland-Nail, P., 1988. Seasonnality of reproduction in sheep and its control by photoperiod. Australian Journal of Biological Sciences. 41: 69-85.

Palmer, M.A., Olmosb, G., Boyleb, L.A., Mee, J.F., 2010. Oestrus detection and oestrus characteristics in housed and pastured Holstein-Friesian cows. Theriogenology. 74: 255-264.

Parson, S.D., Hunter, G.L., 1967. Effect of the ram on duration of oestrus in the ewe. J. Reprod. Fertil. 14, 61-70.

Peralta, O.A., Pearson, R.E., Nebel, R.L., 2005. Comparison of three oestrus detection systems during summer in a large commercial dairy herd. Anim. Reprod. Sci. 1-2, 5972.

Price, E.O., Erhard, H., Dally, MR., 1992. Measures of libido and their relation to serving capacity in the ram. Journal of animal science. 70, 3376-80.

Price, E.O., Bench, C.J., Borgwardt, R.E., Dally, M.R., 2000. Sexual performance of twin ram lambs and the effect of number and sex of contemporary siblings. Applied Animal Behaviour Science. 68, 199-205.

Radford, H.M., Watson, R.H., Wood, G.F., 1960. A Crayon and Associated Harness for the Detection Op Mating Under Field Conditions. Australian Veterinary Journal. 36, 57-66.

Saint-Dizier, M., Chastant-Maillard, S., 2012. Towards an automated detection of oestrus in dairy cattle. Reprod. Domest. Anim. 47, 1056-1061.

Saumande, J., 2002. Electronic detection of oestrus in postpartum dairy cows: efficiency and accuracy of the DEC® (showheat) system. Livest. Prod. Sci.77, 265-271.

Stellflug, J.N., Lewis, G.S., Moffet, C.A., Leeds, T.D., 2008. Evaluation of three-ram cohort serving capacity tests as a substitute for individual serving capacity tests. J. Anim. Sci. 86, 2024-2031.

Teyssier, J., Migaud, M., Debus, N., Maton, C., Tillard, E., Malpaux, B., Chemineau, P., Bodin, L., 2011. Expression of seasonality in Merinos d'Arles ewes of different genotypes at the MT1 melatonin receptor gene. Animal. 5, 329-336. 
Tilbrook, A.J., 1987. The influence of factors associated with oestrus on the sexual “attractiveness" of ewes to rams. Applied Animal Behaviour Science. 17, 117-128.

Umberger, S.H., Jabbar, G., Lewis, G.S., 1994. Seasonally anovulatory ewes fail to respond to progestogen treatment in the absence of gonadotropin stimulation. Theriogenology. 42, 1329-1336.

Valenza, A., Giordano, J.O., Lopes, Jr G., Vincenti, L., Amundson, M.C., Fricke, P.M., 2012. Assessment of an accelerometer system for detection of oestrus and treatment with gonadotropin-releasing hormone at the time of insemination in lactating dairy cows. J. Dairy Sci. 95, 7115-7127. 
Figure captions

Figure 1. Schematic representation of the experimental design (D, day). Two groups of 6 Merinos d'Arles ewes were placed with a vasectomized ram, equipped with the electronic device, either at their first oestrous cycle (C1), i.e. just after oestrus synchronization (FGA and eCG), or during their following natural oestrus (C2).

Figure 2. Picture of the complete electronic oestrus detection system in the sheep. a) a leather harness containing an Alpha Detector (AD), b) an Alpha Reader (AR) which is used to remotely transfer data from each $\mathrm{AD}$ carried by rams each time one wants to know the ewes that accepted mountings and AR also allows to read the RFID ear tag number and write it on a RFID transponder that is placed near the tail of each ewe, c) picture showing a ram mounting a ewe in oestrus, the harness is tight around the chest of the ram so that $\mathrm{AD}$ can read the transponder of the ewe.

Figure 3. Oestrus expression in hormonally induced ewes during their first cycle (C1) and during their following natural estrous cycle (C2). Each curve corresponds to one ewe. The cumulated mountings obtained by video observations (VO) for each ewe served as the reference i.e. the whole cumulated curve. Symbols in normal size were both observed by VO and collected by Alpha Detector while smaller symbols indicate mounts that were not detected by AD. The 00:00 time in C2 refers to day17 after withdrawal of the sponges in $\mathrm{C} 1$. The shaded area (C1) indicates the time of AD malfunctioning in C1.

Figure 4. Male (M1 vs. M2) activities during two successive oestrous cycles (C1 vs. C2). Intensity of male behavior is expressed in total number of mounts observed with VO. indicates significant differences between groups $(\mathrm{p}<0.05)$.

Figure 5: Cumulated numbers of readings by a ram equipped with the Alpha-Detector during Trial 2. Each curve corresponds to one ewe. Two ewes were read more than 140 times (in fact 205 and 157 times). Two intact rams of the same breed were successively used (namely $\left.\mathrm{n}^{\circ} 6061 \mathrm{n}^{\circ} 1429\right)$. 


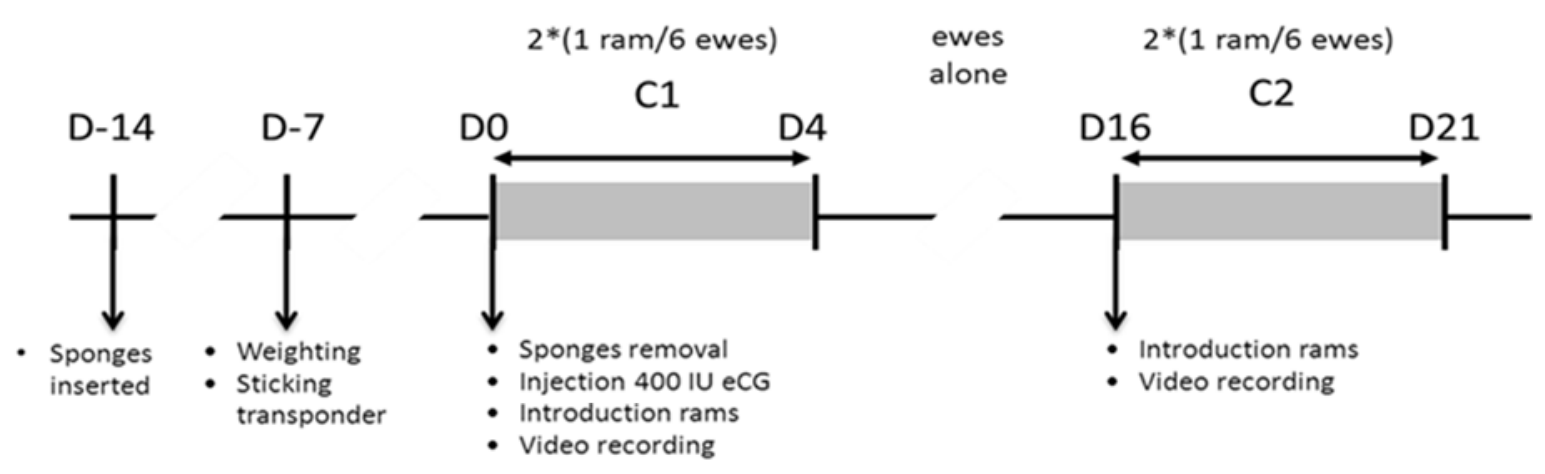

Fig 1 


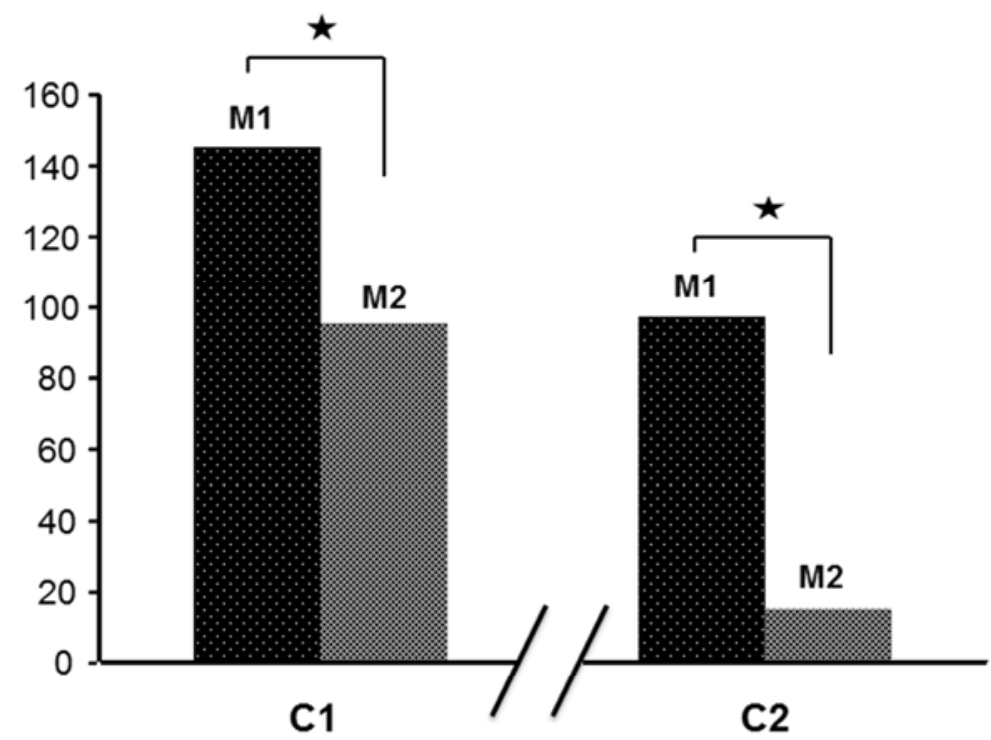

Fig 2 


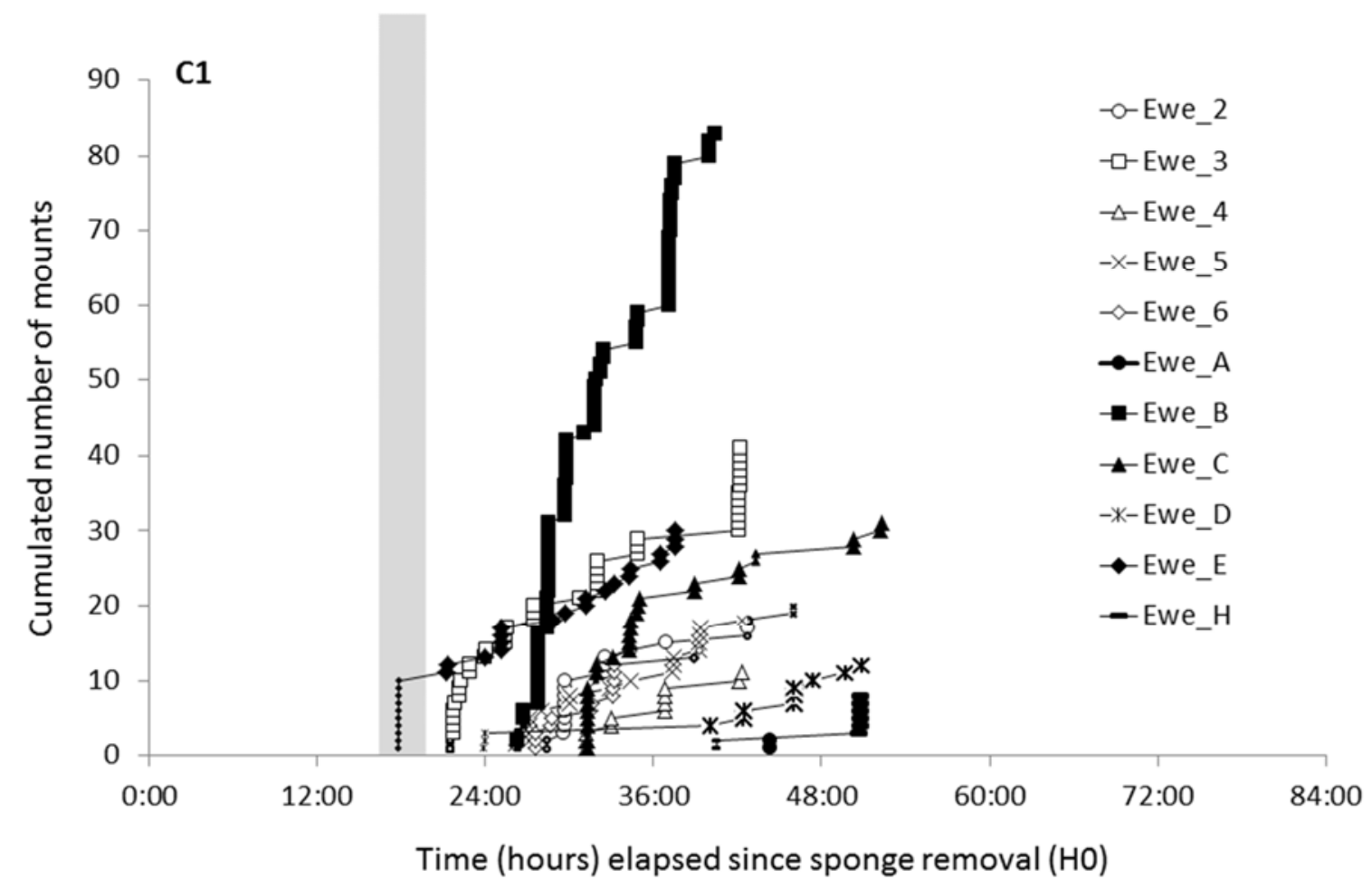

Fig 3 


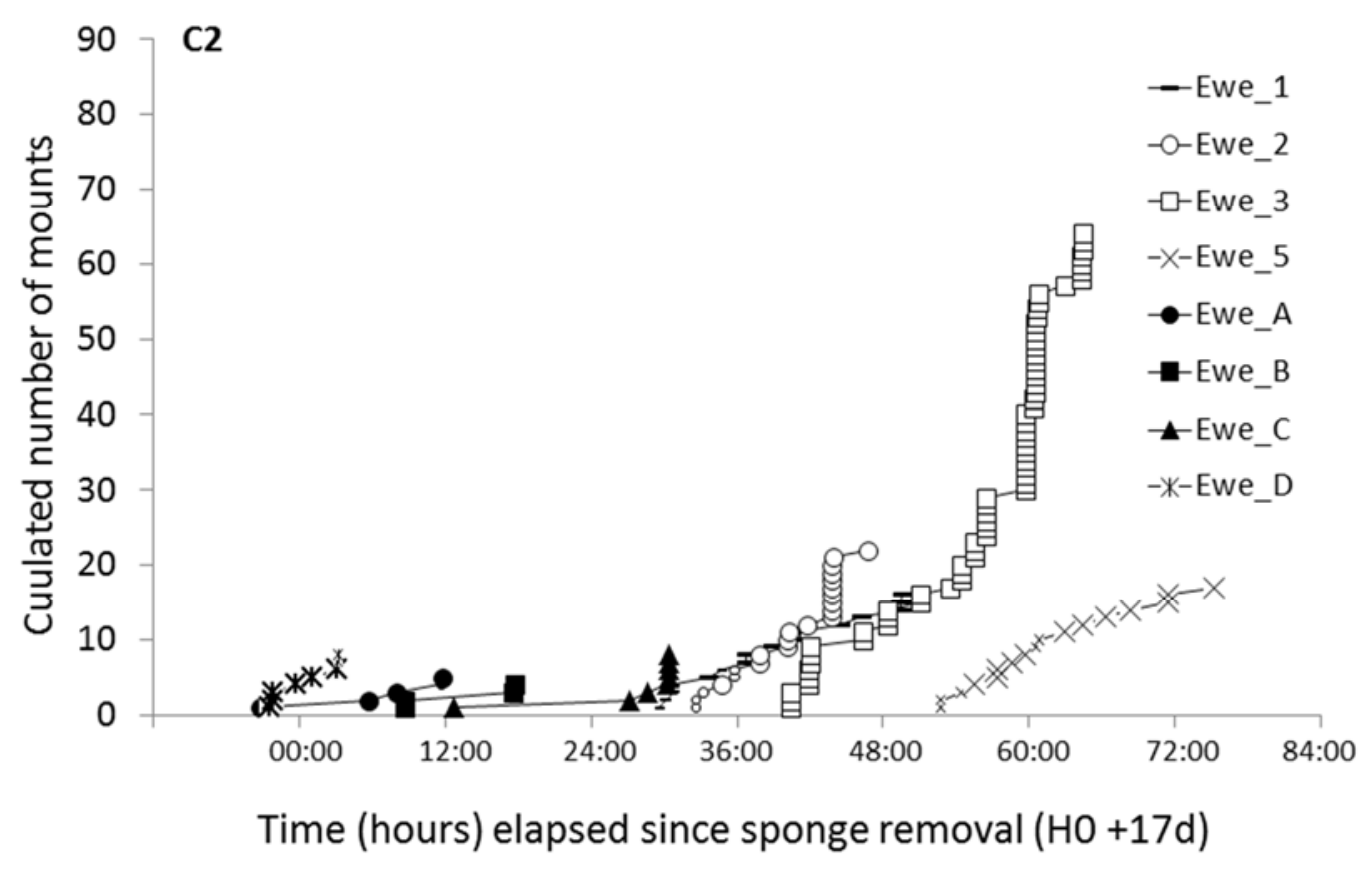

Fig 4 


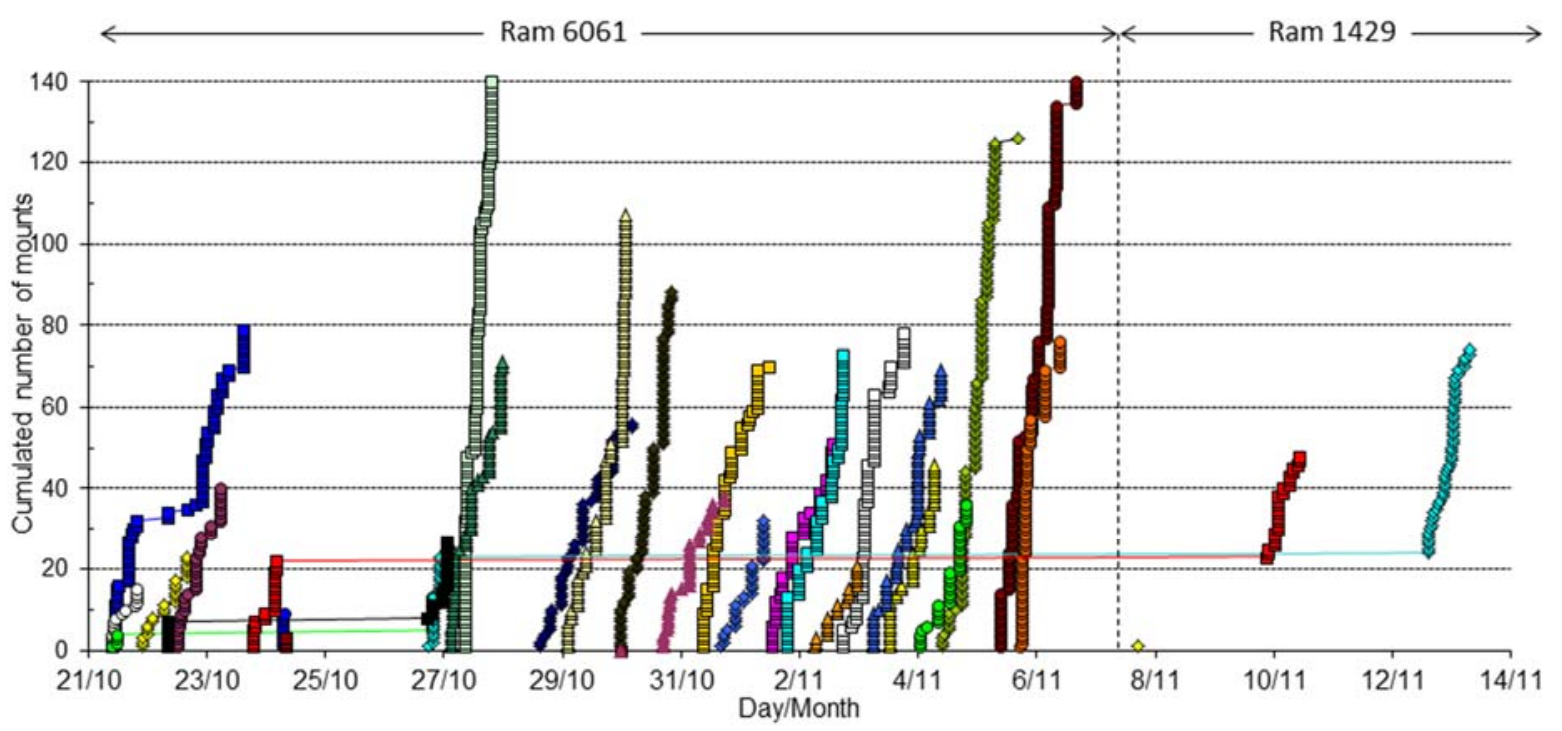

Fig 5 